\title{
Stable plastid transformation in lettuce (Lactuca sativa L.)
}

\author{
Cilia L.C. Lelivelt ${ }^{1, \dagger}$, Matthew S. McCabe ${ }^{2, \dagger}$, Christine A. Newell ${ }^{3}$, C. Bastiaan de Snoo ${ }^{1}$, \\ Kees M.P. van Dun ${ }^{1}$, Ian Birch-Machin ${ }^{3,5, \dagger}$, John C. Gray ${ }^{3}$, Kingston H.G. Mills ${ }^{4}$ and \\ Jacqueline M. Nugent ${ }^{2, *}$ \\ ${ }^{1}$ Rijk Zwaan Breeding B.V., $I^{e}$ Kruisweg 9, 4793 RS, Fijnaart, The Netherlands; ${ }^{2}$ Institute of Bioengineering \\ and Agroecology National University of Ireland, Maynooth, Co. Kildare, Ireland (*author for correspon- \\ dence; e-mail jackie.nugent@nuim.ie); ${ }^{3}$ Department of Plant Sciences, University of Cambridge, Downing \\ Street, CB2 3EA, Cambridge, UK; ${ }^{4}$ Department of Biochemistry, Trinity College, Dublin 2, Ireland; \\ ${ }^{5}$ Department of Anatomy, University of Cambridge, Downing Street, CB2 3DY, Cambridge, UK ${ }^{\dagger}$ These two \\ authors contributed equally to the project
}

Received 28 February 2005; accepted in revised form 20 May 2005

Key words: aadA, lettuce, PEG, plastid transformation, $\operatorname{trnI} / \operatorname{trn} A$

\begin{abstract}
Although plastid transformation in higher plants was first demonstrated in the early 1990s it is only recently that the technology is being extended to a broader range of species. To date, the production of fertile transplastomic plants has been reported for tobacco, tomato, petunia, soybean, cotton and Lesquerella fendleri (Brassicaceae). In this study we demonstrate a polyethylene glycol-mediated plastid transformation system for lettuce that generates fertile, homoplasmic, plastid-transformed lines. Transformation was achieved using a vector that targets genes to the $\operatorname{trn} A / \operatorname{trn} I$ intergenic region of the lettuce plastid genome employing the aadA gene as a selectable marker against spectinomycin. Spectinomycin resistance and heterologous gene transcription were shown in $\mathrm{T}_{1}$ plants derived from self-pollinated primary regenerants demonstrating transmission of the plastid-encoded transgene to the first seed generation. Crossing with male sterile wild-type lettuce showed that spectinomycin resistance was not transmitted via pollen. Constructs containing the $g f p$ gene showed plastid-based expression of green fluorescent protein. The lettuce plastid could have potential both as a production and a delivery system for edible human therapeutic proteins.
\end{abstract}

\section{Introduction}

Plastid transformation was first reported in the green alga Chlamydomonas (Boynton et al., 1988) and the technology was soon applied to the higher plant species tobacco (Nicotiana tabacum) (Svab et al., 1990). Plastid transformation offers significant advantages over nuclear transformation technology including the potential for very high levels of expression of heterologous protein (De Cosa et al., 2001; Tregoning et al., 2003), transgene containment due to materal inheritance of cytoplasmic genomes in most higher plants (Svab and Maliga 1993; Birky 2001; Ruf et al., 2001; Skarjinskaia et al., 2003), lack of position effects due to targeted integration events (Staub and Maliga 1992) lack of gene silencing, and co-expression of multiple genes because the plastid translational machinery has the capacity to translate polycistronic transcripts (Staub and Maliga 1995; De Cosa et al., 2001). However, despite these advantages it has taken nearly a decade to extend plastid transformation technology to higher plants other than tobacco. 
Both biolistic bombardment of leaves (Svab et al., 1990) and polyethylene glycol (PEG) treatment of protoplasts (Golds et al., 1993; O'Neill et al., 1993) have been used for DNA delivery into plant plastids. Plastid transformation involves targeted integration of a foreign gene, or genes, into the plastid genome via homologous recombination. Plastid genomes are highly polyploid (Bendich, 1987) with each plastid containing between 10 and 100 genome equivalents. The number of plastids per cell varies considerably (Pyke, 1999) and cells that are specialized for photosynthesis (e.g. mesophyll leaf cells) can have hundreds of these organelles. Stable transformation requires that all copies of the plastid genome are transformed (homoplasmic state) and that all wild-type copies of the plastid genome are eliminated by selection.

Tobacco plastid transformation is now routine in many labs and is the benchmark for assessing plastid transformation protocols developed for other plant species. Plastid transformation has also been achieved in the related solanaceous species, tomato, potato and petunia using tobacco vectors (Sidorov et al., 1999; Ruf et al., 2001; Zubko et al., 2004), albeit at a significantly lower transformation efficiency than in the tobacco system, in the case of potato the transformed plants were sterile (Sidorov et al., 1999). Plastid transformation in non-solanaceous species has been more difficult to obtain. Transformation of Arabidopsis thaliana plastids has been achieved but the transformation frequency was low and the transformed plants were sterile (Sikdar et al., 1998). Lesquerella fendleri (Brassicaceae) was transformed using a chimeric Arabidopsis/tobacco vector and resulted in a low frequency of fertile, transformed plants (Skarjinskaia et al., 2003). Recently, fertile transplastomic plants were generated in cotton (Kumar et al., 2004a) and soybean (Dufourmantel et al., 2004b) using species-specific vectors. Plastid transformation of carrot cell cultures was achieved using a carrot vector but there is no indication that the transformed plants were fertile (Kumar et al., 2004b). A Brassica napus (oilseed rape) vector was used to transform oilseed rape but only heteroplasmic plastid transformed lines were obtained (Hou et al., 2003). Likewise, plastid transformation of embryonic rice suspension culture cells, using a rice chloroplast DNA vector, resulted in plants that were heteroplasmic for the chloroplast insertion (Khan and Maliga, 1999).

There is significant interest in plastid-based recombinant protein production in non-toxic, edible plant species not only to minimize downstream protein processing costs but also to develop a combined production and delivery system for 'edible' protein therapies. Lettuce (Lactuca sativa L.) is a commercially important crop belonging to the Asteraceae. The leaves of this crop are consumed raw by humans and the time from sowing seed to edible biomass is only weeks compared to months for crops such as tomato or potato. Here we report production of fertile, homoplasmic, plastid-transformed lines in lettuce using a transformation vector that targets the $\operatorname{trnI} / \operatorname{trn} A$ region of the lettuce plastid genome. In addition, we show detectable expression of recombinant green fluorescent protein in lettuce plastids. The successful transformation of lettuce plastids offers the potential to develop lettuce both as a production and a delivery system for human therapeutic proteins such as subunit vaccines.

\section{Materials and methods}

\section{DNA sequencing}

Lettuce chloroplast DNA SacI clones 6 and 15 (Jansen and Palmer, 1987) were obtained from Prof. Bob Jansen, University of Texas, Austin, USA and partially sequenced. DNA sequencing was carried out using the ABI Prism BigDye terminator cycle sequencing ready reaction kit according to the manufacturers instructions (Applied Biosystems) and an ABI Prism 3310 genetic analyzer (Applied Biosystems). The lettuce sequence has been deposited in GenBank under the accession number DQ013044.

\section{Vector and expression cassette construction}

Plasmid LCV2 contains a 2253 bp lettuce chloroplast DNA target sequence cloned into a pCR2.1 backbone vector (Invitrogen). The target sequence extends from the rrn16/trnI intergenic region to the $\operatorname{trn} A / r r n 23$ intergenic region and corresponds to nucleotide (nt) positions 104366-106260 in the tobacco chloroplast genome sequence (Wakasugi et al., 1998). The target sequence was amplified in 
two parts to introduce unique $P a c \mathrm{I}$ and $A s c \mathrm{I}$ restriction sites in the $\operatorname{trnI} / \operatorname{trn} A$ intergenic region at a position corresponding to nt 105370 in the tobacco chloroplast genome sequence (Wakasugi et al., 1998). The trnI gene region was PCR amplified from lettuce chloroplast DNA using the PCR primers 5'-TCGACAGTGAAGTAAGACCAAG$3^{\prime}$ and $5^{\prime}$-GGCGCGCCTTAATTAAGGAGTCA GACGCTTCTTCTATTC-3' (PacI and AscI restriction sites underlined) and cloned into pCR2.1 to create pCR2.1-trnI. The trnA gene region was PCR amplified using the primer combination 5'-TTAATTAAGGCGCGCCCATGCATGCTCCACTTGGCTCGG-3' (PacI and AscI restriction sites underlined) and 5'-CATGAATGATAAATCATAGATCGAAC- $3^{\prime}$. The amplified $\operatorname{trn} A$ gene region was cloned into pCR2.1 to create pCR2.1$\operatorname{trn} A$. The $\operatorname{trn} A$ gene region was excised from pCR2.1-trn $A$, using $P a c \mathrm{I}$ and $X b a \mathrm{I}$, and was introduced into the $P a c I$ and $X b a I$ sites in pCR2.1-trnI to create $\mathrm{pLCV} 2$. The $\operatorname{trn} I / \operatorname{trn} A$ insert was sequenced in pLCV2 to confirm that the target sequence was identical to the corresponding lettuce plastid genome sequence except for the inclusion of $\mathrm{PacI}$ and AscI restriction sites. The pLCV2 insert sequence has been deposited in GenBank under the accession number AY943927.

Plasmid LCV2-GFP/aadA containing $g f p$ and aadA expression cassettes was produced by first inserting the aadA expression cassette from pZS197 (Svab and Maliga, 1993) into pLCV2 to yield pLCV2-aadA. The expression cassette included the tobacco $r r n$ promoter (with an 18 bp synthetic leader and ribosome-binding site, Svab and Maliga, 1993), the aadA coding region, and the tobacco $p s b A 3^{\prime}$ region amplified by PCR using forward (5'GATCGAGGCGCGCCGGAGCCCGGAACTAGCTGCTGC) and reverse (5'-ATTTTCGGCG CGCCCCCACACCTGCGTTCGAACTCCTTC) primers both of which contained flanking $A s c$ I sites (underlined). The AscI-digested PCR product was inserted into dephosphorylated AscI-digested pLCV2 and recombinant $E$. coli clones were selected on spectinomycin. pLCV2-GFP/aadA was then produced by inserting a $g f p$ expression cassette into the PacI site of pLCV2-aadA. The $g f p$ expression cassette contained the tobacco $r r n$ promoter (with $r b c L 5^{\prime}$ UTR and ribosome-binding site), the smgfpcoding region, and the E. coli $\operatorname{rrn} B$ terminator (Newell et al., 2003) and was amplified by PCR from a pZS197-based plasmid containing Prrn-gfp
(Newell et al., 2003) using forward (5'-GATCTTAATTAAGCTCCCCCGCCGTCGTTCAATG) and reverse (5'-GATCTTAATTAAGTCG ACAACACGGGATAATACCGCGC) primers containing flanking PacI sites (underlined). The PacI-digested PCR product was inserted into dephosphorylated PacI-digested pLCV2-aadA to yield $\mathrm{pLCV} 2-\mathrm{GFP} / \mathrm{aadA}$.

The LEC1 expression cassette contains the aad $A$ gene and the influenza virus haemagglutinin gene $(H A)$ under the control of the lettuce $r r n$ operon promoter (PLs-rrn) and lettuce psbA $3^{\prime} \mathrm{UTR}\left(3^{\prime} L s-p s b A\right)$. A chloroplast ribosome-binding site (GGAGG) precedes both genes. The lettuce ribosomal RNA operon promoter (PLs$r r n)$ was amplified from the lettuce chloroplast DNA $S a c$ I clone 6 using the PCR primer pair 5'-TCGAGCTCTTAATTAAGCTACCCCGCCGTGATTGAATGAGAAT- $3^{\prime}$ and 5'-AAATCCC TCCCTACAACTGTATCCAAGCGCTTCGTATTCGC- $3^{\prime}$ ( $S a c \mathrm{I}$ and $P a c \mathrm{I}$ restriction sites underlined). The aadA gene, including synthetic leader and ribosome-binding site was amplified from the tobacco chloroplast transformation vector pZS197 (Svab and Maliga, 1993) using the PCR primer pair 5'-GTTGTAGGGAGGGATTTATGGCAGAAGCGGTGATCGCCGAA- ${ }^{\prime}$ and 5'-TCGCGGCCGCTTATTTGCC GACTAC CTTGGTGAT-3' (NotI restriction site underlined). The PLs-rrn was joined to the $5^{\prime}$ end of the $\operatorname{aadA}$ gene by overlap extension and the $\mathrm{P} L s$-rrn/aadA fusion was cloned into the $S a c \mathrm{I}$ and NotI sites in the polylinker of pBS SK + (Stratagene). The $H A$ gene (mature coding region) was amplified using the PCR primer pair 5'TCGCGGCCGCAGTTGTAGGGAGGGATTTATGCAAAAACTTCCCGGAAATGACAA-3' and 5'-GGATCCTTAGTATCCTGACTTCAGCTCAAC-3' from cloned $H A$ template DNA (Johnson et al., 2000). These primers incorporate a NotI site (underlined) and a short leader sequence and ribosome-binding site at the $5^{\prime}$ end of the $H A$ gene and a BamHI site (underlined) at the $3^{\prime}$ end of the $H A$ gene. The PCR fragment was cloned into the $\operatorname{Not} /$ /BamHI sites in pBS SK + to give pBS-HA. The lettuce $p s b A 3^{\prime} \mathrm{UTR}\left(3^{\prime} L s-p s b A\right)$ was PCR amplified from lettuce chloroplast DNA (cv. Evola) using primers 5'-AACATTTAAGGATCCGACTTTGGTCTTATTGTAATTGTATAG3' and 5'-ATCTGCAGGGCGCGCCAT CCACTTGGCTACATCCGCC $3^{\prime}$. These primers 
incorporate a Bam $\mathrm{HI}$ site (underlined) at the $5^{\prime}$ end of the $3^{\prime} L s-p s b A$ and PacI and PstI sites (underlined) at the $3^{\prime}$ end of the $3^{\prime} L s-p s b A$. The $3^{\prime} L s-p s b A$ sequence was fused to the $3^{\prime}$ end of the $H A$ gene by cloning into the Not $\mathrm{I} /$ Pst $\mathrm{I}$ sites in pBS-HA. The $H A / 3^{\prime} L s-p s b A$ construction was excised from pBS SK + and cloned downstream of the aadA gene in pBS SK + PLrrn/aadA using NotI and PstI restriction sites. The entire LEC1 cassette (PLs-rrn/aadA/HA/3'Ls-psbA) was excised from pBS SK + and cloned into the $P a c \mathrm{I} /$ $A s c$ I sites in pLCV2 to create pLCV2-LEC1.

\section{Protoplast isolation, transformation and culture}

Lettuce seeds cv. Flora were sterilized in $70 \%$ ethanol, $0.7 \%$ hypochlorite solution for $20 \mathrm{~min}$, washed three times in sterile demineralized water, and sown on MS medium $(0.7 \%$ microagar, Duchefa; Murashige and Skoog, 1962) supplemented with $2 \%$ sucrose, without hormones. Seeds were cultured at $15^{\circ} \mathrm{C}$ for 2 days in the dark, after which they were transferred to $25^{\circ} \mathrm{C}$ in the light $\left(60 \mu \mathrm{mol} \mathrm{m} \mathrm{m}^{-2} \mathrm{~s}^{-1}\right.$, photoperiod $16 \mathrm{~h}$ light $/ 8 \mathrm{~h}$ dark). When the first true leaves appeared, the shoot tips were transferred to MS medium with 3\% sucrose without hormones and grown under the same conditions $\left(25^{\circ} \mathrm{C}, 16 \mathrm{~h}\right.$ light $/ 8 \mathrm{~h}$ dark $)$. Protoplasts were isolated from 3-week-old shootculture leaves. The leaves were cut into pieces, approximately $25-50 \mathrm{~mm}^{2}$ in size, and incubated in the dark for $1 \mathrm{~h}$ in PG solution (Glimelius, 1984). The PG solution was replaced with an enzyme solution consisting of $1 \%$ cellulase (Brunschwig, Switzerland) and 0.25\% macerozyme (Brunschwig, Switzerland) in B5 medium (Gamborg et al., 1968) and the leaf pieces were incubated for $16 \mathrm{~h}$ in the dark at $25^{\circ} \mathrm{C}$. The protoplast suspension was filtered through a $41 \mu \mathrm{m}$ nylon mesh filter and washed with one third volume of CPW16S solution (Frearson et al., 1973). Protoplasts were collected at the surface following centrifugation at $70 \times g$ for $8 \mathrm{~min}$. Isolated protoplasts were washed in W5 solution (Menczel et al., 1981) and pelleted following centrifugation at $70 \times g$ for $5 \mathrm{~min}$. Protoplasts were diluted to a density of approximately $1-1.5 \times 10^{6}$ protoplasts per $0.4-0.6 \mathrm{ml}$ of transformation buffer (Datta and Datta, 1999).
Ten microliters of transforming DNA $(1 \mu \mathrm{g} / \mu \mathrm{l}$ in $10 \mathrm{mM}$ Tris, $1 \mathrm{mM}$ EDTA $\mathrm{pH} 8.0$ ) and $0.4-$ $0.6 \mathrm{ml}$ PEG 6000 solution (Datta and Datta, 1999) was added to the protoplast suspension and incubated at room temperature for $10 \mathrm{~min}$. The protoplasts were then diluted in wash solution (Datta and Datta, 1999), pelleted by centrifugation at $70 \times g$ for $8 \mathrm{~min}$, then resuspended in $1 / 2 \mathrm{~B} 5$ culture medium (Gamborg et al., 1968) supplemented with $375 \mathrm{mg} / \mathrm{l} \quad \mathrm{CaCl}_{2} \cdot 2 \mathrm{H}_{2} \mathrm{O}$, $18.35 \mathrm{mg} / \mathrm{l} \quad \mathrm{NaFeEDTA}, \quad 270 \mathrm{mg} / \mathrm{l}$ sodium succinate, $103 \mathrm{~g} / 1$ sucrose, $0.1 \mathrm{mg} / 1$ 2,4 dichlorophenoxyacetic acid (2,4-D), $0.3 \mathrm{mg} / 1$ 6-benzylaminopurine (BAP) and $0.1 \mathrm{~g} / 1$ MES. The protoplasts were mixed with a $1: 1$ solution of $1 / 2 \mathrm{~B} 5$ medium and $2 \%$ agarose to a culture density of $3-6 \times 10^{4}$ protoplasts per $\mathrm{ml}$. The agarose/protoplast suspension was plated onto $3.5 \mathrm{~cm}$ Petri dishes, overlaid with $4 \mathrm{ml}$ of liquid $1 / 2 \mathrm{~B} 5$ culture medium and cultured at $25^{\circ} \mathrm{C}$ in the dark without selection. Selection for transformed microcalli was initiated after 6 days by replacing the liquid culture medium with fresh medium containing spectinomycin dihydrochloride $(500 \mathrm{mg} / \mathrm{l})$ and incubating at $25^{\circ} \mathrm{C}$ in the dark. One week after initiation of selection, the culture medium was replaced with fresh liquid medium containing spectinomycin dihydrochloride $(500 \mathrm{mg} / \mathrm{l})$ and the cultures were transferred to the light $(16 \mathrm{~h} \mathrm{light} / 8 \mathrm{~h}$ dark $)$ at $25^{\circ} \mathrm{C}$.

When the calli were approximately $0.5 \mathrm{~mm}$ in diameter they were transferred to callus-growth medium (Schenk and Hildebrandt, 1972) supplemented with $30 \mathrm{~g} / 1$ sucrose, $5 \mathrm{~g} / 1$ agarose, $0.1 \mathrm{mg} / 1$ 1-naphthalene acetic acid (NAA), $0.1 \mathrm{mg} / 1$ benzylaminopurine (BAP), and $500 \mathrm{mg} / 1$ spectinomycin dihydrochloride. When the calli had grown to a few $\mathrm{mm}$ in diameter they were transferred to regeneration medium (Schenk and Hildebrandt, 1972) supplemented with $15 \mathrm{~g} / 1$ sucrose, $15 \mathrm{~g} / 1$ maltose, $0.1 \mathrm{mg} / 1$ NAA, $0.1 \mathrm{mg} / 1$ BAP and $500 \mathrm{mg} / 1$ spectinomycin dihydrochloride. Culture conditions were as described above. Shoots regenerated after approximately 6 weeks and were transferred onto SH medium (Schenk and Hildebrandt, 1972) supplemented with $30 \mathrm{~g} / 1$ sucrose, $8 \mathrm{~g} / 1$ microagar and $500 \mathrm{mg} / 1$ spectinomycin dihydrochloride. Ploidy level of callus and regenerated plant tissue was determined by flow cytometric analyses (Partec, Munster). 
PCR analyses of spectinomycin-resistant cell lines and shoots

The presence of the aadA gene was assessed in spectinomycin-resistant cell lines by PCR analysis using gene-specific primers (aadAF-5'-TATGACGGGCTGATACTGGGC-3' and aadAR 5'-AAGTCACCATTGTTGTGCACG-3'). The presence/absence of the $g f p$ gene was assessed by PCR in pLCV2-GFP/aadA-transformed cell lines that showed no GFP expression using a trnI genespecific primer (5'-TCGACAGTGAAGTAAGACCAAG-3') and an $\operatorname{aad} A$-gene specific primer (5'-CTACATTTCGCTCATCGGC-3'). The PCR products were sequenced commercially by AGOWA, GmbH, Germany. To confirm plastid integration of entire vector/expression cassette constructs in pLCV2-LEC1-transformed callus lines and shoots PCR was carried out using primers designed against genomic DNA sequences that flank the vector integration site on the lettuce plastid genome (For: 5'-ACTGGAAGGTGCGGCTGGAT-3' and Rev: 5'-CTCGCCCTTAATT TTAAGGC-3'). In some cases, precise genome/ vector junctions were confirmed by PCR using combinations of flanking primers and expression cassette-specific primers.

\section{Immunoblot analysis}

Total protein was extracted from frozen callus or leaf tissue in extraction buffer $[60 \mathrm{mM}$ Tris- $\mathrm{HCl}$, pH 8.0, $500 \mathrm{mM} \mathrm{NaCl}, 10 \mathrm{mM} \mathrm{Na}_{2}$ EDTA, $30 \mathrm{mM}$ 2-mercaptoethanol, $0.1 \mathrm{mM}$ phenylmethanesulfonyl fluoride or $2 \times$ Complete $^{\mathrm{TM}}$ protease inhibitor (Roche Diagnostics, UK)]. The proteins were separated by SDS-12\% PAGE, transferred to polyvinylidene difluoride (PVDF) membrane by electroblotting and the membrane was blocked overnight with $2 \%$ non-fat dry milk. For HA detection, the blots were incubated with sheep anti-HA Sichuan 1987 polyclonal antiserum (supplied by National Institute for Biological Standards and Control, UK) followed by donkey anti-sheep HRP-conjugated secondary antibody (Sigma). For GFP detection, the blot was incubated with rabbit antiserum to GFP (Abcam) and immunoreactive bands detected by enhanced chemiluminescence (Amersham). GFP protein standards were supplied by Clontech.

\section{Microscopy analysis}

A small piece of callus was chopped finely, teased out on a microscope slide and mounted in water. Plastids were examined by laser scanning confocal microscopy (TCS-NT, DM1RB light microscope stand, Leica). Excitation wavelengths were set at $488 \mathrm{~nm}$ and $568 \mathrm{~nm}$, and images collected through FITC and TRITC filters, for chlorophyll and GFP fluorescence, respectively. In order to combine images for chlorophyll and GFP fluorescence, data were imported into Adobe Photoshop and merged.

\section{Southern blot analysis}

Total DNA was isolated from leaves of wild-type and transplastomic lettuce plants with a GenElute Plant Genomic DNA Kit (Sigma-Aldrich). Purified DNA (approx. $0.3 \mu \mathrm{g}$ ) was digested with $\mathrm{SacI}$ overnight. Digested DNA fragments were separated by electrophoresis on a $0.7 \%$ agarose gel and transferred to a nylon membrane using standard blotting procedures (Southern, 1975). A trnI probe was generated by digesting pLCV2 with EcoRI and $S a c I$ to release a $1.3 \mathrm{~kb}$ fragment that was gel purified using a Qiaquick Gel Extraction Kit (Qiagen). A $1.7 \mathrm{~kb} H A$ gene-specific probe was generated by PCR using pBS-HA as template and M13 forward and reverse primers. The PCR product was gel purified using a Qiaquick Gel Extraction Kit (Qiagen). Probe DNA was labeled with $\left[\alpha-{ }^{32} \mathrm{P}\right] \mathrm{dATP}$ by random priming using a Prime-It II Random Primer Labeling Kit (Stratagene). Prehybridization, hybridization overnight at $65^{\circ} \mathrm{C}$ to ${ }^{32} \mathrm{P}$-labelled probes, and subsequent washing of the membrane was carried out according to the manufacturer's instructions. The membrane was probed initially with the trnI fragment, then stripped and re-probed with the $H A$ gene fragment.

\section{Northern blot analysis}

Total RNA was extracted from leaves of wildtype and transplastomic lettuce plants using Tripure Isolation Reagent (Boehringer Mannheim). RNA (10 $\mu \mathrm{g})$ was denatured by treatment with formaldehyde and separated by electrophoresis on a $1 \%$ agarose/formaldehyde gel. The gel was transferred to GeneScreen Plus nylon membrane overnight. The same HA probe described 
above was used to probe the membrane for a HA transcript. The aadA probe was generated by PCR and the DNA fragment was gel isolated and labeled as described above. The membrane was prehybridized, hybridized overnight at $42{ }^{\circ} \mathrm{C}$, and then washed according to the manufacturer's instructions. The membrane was probed initially with the HA gene fragment, stripped, and re-probed with the aadA fragment.

\section{Testing seedlings for spectinomycin resistance}

Seeds were surface sterilized and sown on MS medium $(0.7 \%$ microagar, Duchefa; Murashige and Skoog, 1962) supplemented with $2 \%$ sucrose and $500 \mathrm{mg} / 1$ spectinomycin dihydrochloride. Seedlings were grown at $25{ }^{\circ} \mathrm{C}$ in the light $\left(60 \mu \mathrm{mol} \mathrm{m}^{-2} \mathrm{~s}^{-1}\right.$, photoperiod $16 \mathrm{~h}$ light $/ 8 \mathrm{~h}$ dark). After 2 weeks, non-transformed seedlings were yellow, whereas spectinomycin-resistant seedlings were green and showed vigorous growth.

\section{Results}

Approximately $8.2 \mathrm{~kb}$ of the lettuce chloroplast DNA inverted repeat region was sequenced (Figure 1A) and PCR primers based on these DNA sequence data were used to construct candidate lettuce plastid transformation vectors. pLCV2 contains a 2253 bp lettuce chloroplast DNA target sequence inserted into a pCR2.1 backbone vector (Figure 1B). pLCV2 targets insertions in the trnI and $\operatorname{trn} A$ intergenic region of the $r r n$ operon and is based on the universal pSBL vector series (Daniell et al., 1998; De Cosa et al., 2001). The LCV2 insert sequence is $97 \%$ similar to the corresponding tobacco chloroplast DNA sequence over most of its length. However, the lettuce trnI intron has a $231 \mathrm{bp}$ segment that is not present in the tobacco sequence and the $\operatorname{trn} A$ intron has a $101 \mathrm{bp}$ segment that is also absent in the tobacco sequence.

A trial construct containing the aminoglycoside 3'adenylyltransferase $(\mathrm{aad} A)$ and green fluorescent protein $(g f p)$ genes was used to develop a lettuce plastid transformation procedure and to demonstrate plastid-based expression of heterologous proteins in lettuce. The GFP/aadA expression cassette, containing the $g f p$ and aadA genes under the control of identical tobacco $r r n$ promoters (Prrn; Figure 1C), was introduced into pLCV2 at
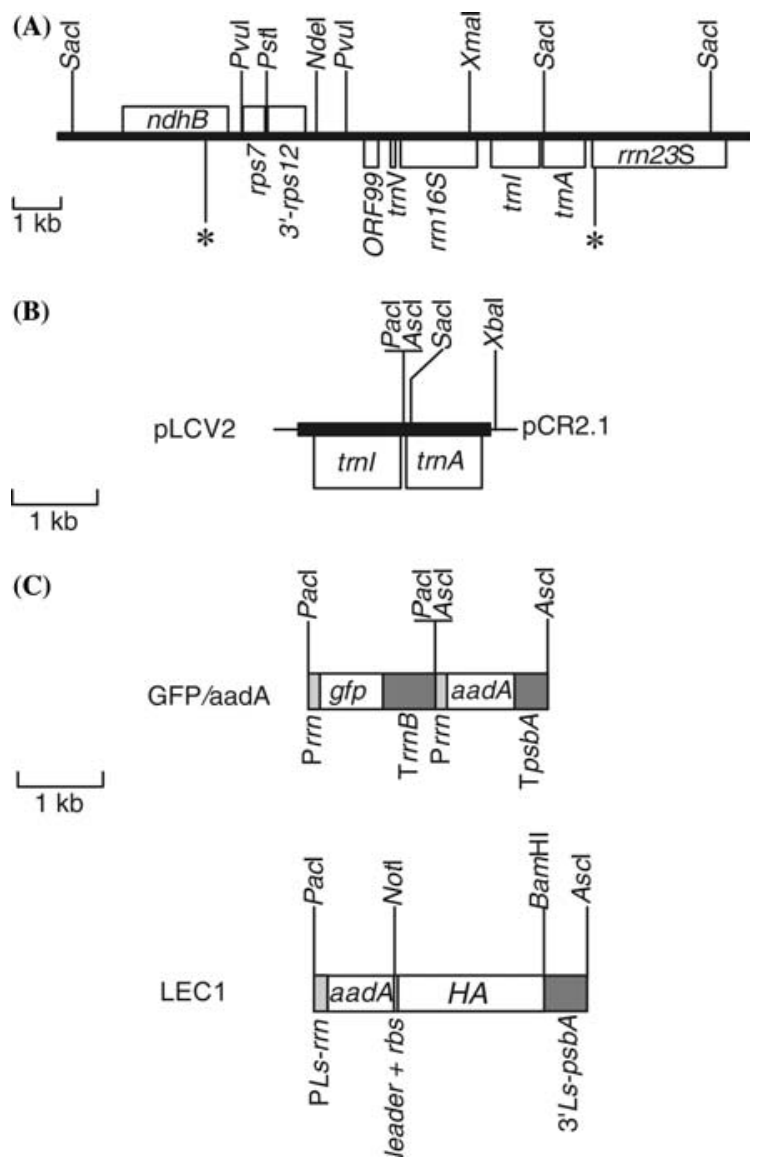

Figure 1. Vector and expression cassettes used for lettuce plastid transformation. (A) Physical and restriction map of the region of the lettuce chloroplast genome used for vector construction (region sequenced is delineated by *). (B) Map of $\mathrm{pLCV} 2$ showing engineered $\mathrm{PacI} / \mathrm{AscI}$ sites in the intergenic spacer region between the $\operatorname{trnI}$ and $\operatorname{trn} A$ genes. The $1020 \mathrm{bp}$ $\operatorname{trnI}$ gene has an intron at nucleotide position 39-985; the 874 bp trnA gene has an intron at nucleotide position 39-857. (C) Expression cassettes used for lettuce plastid transformation. The GFP/aadA expression cassette contains the $s m g f p$ gene under the control of the tobacco rrn promoter (Prrn) and the aadA gene under the control of a second tobacco $r r n$ (Prrn) promoter. The LEC1 expression cassette contains the aad $A$ gene and influenza virus A $H A$ gene under the control of the lettuce $r r n$ operon promoter (PLs-rrn) and $3^{\prime}$ lettuce $p s b A 3^{\prime}$ sequence $\left(3^{\prime} L s-p s b A\right)$. An 18 bp leader sequence and ribosome-binding site $(r b s)$ are present upstream of the $H A$-coding region.

unique $P a c \mathrm{I}$ and $A s c \mathrm{I}$ cloning sites. The aad $A$ gene confers resistance to spectinomycin and streptomycin when expressed in plastids and is used for the selection of stable transformants (Svab and Maliga, 1993). Lettuce plastid transformation was carried out by PEG-mediated uptake of pLCV2$\mathrm{GFP} / \mathrm{aadA}$ by leaf protoplasts. A protoplast- 
mediated transformation system was preferred over biolistic transformation because stringent selection for transformed plastids was considered more feasible with single cells, or small clumps of cells, than with the larger tissues normally used for biolistic transformation. Protoplasts were initially cultured without selection in the dark before commencing selection on spectinomycin $(500 \mathrm{mg} / \mathrm{l})$ six days post-transformation. One week after initiation of selection, the protoplast cultures were transferred to the light. Green, spectinomycin-resistant callus material developed 4-5 weeks post-transformation (Figure 2A). Nine spectinomycin-resistant cell-lines were regenerated from a total of $5.6 \times 10^{6}$ treated viable protoplasts. The presence of the aadA gene in these cell lines was confirmed by PCR analyses (data not shown). Spectinomycin-resistant calli were propagated on culture medium containing spectinomycin. Plastidbased GFP accumulation was assessed in seven of the nine cell lines by immunoblot analysis of total soluble protein extracted from callus material and by confocal laser scanning microscopy. A $28 \mathrm{kDa}$ immunoreactive protein was detected in protein extracts from two of the callus lines. The level of GFP accumulation in one callus line (GFP/aadA2.2) was estimated at $1 \%$ total soluble protein (TSP) by comparison with known amounts of GFP protein (Figure 3A). Plastid-based GFP accumulation in the GFP/aadA-2.2 callus line was confirmed by confocal laser scanning microscopy which showed discreet plastid-localized GFP fluorescence (Figure 3B). Not all cells in the spectinomycin-resistant callus showed GFP fluorescence; however, in those that did, homogenous
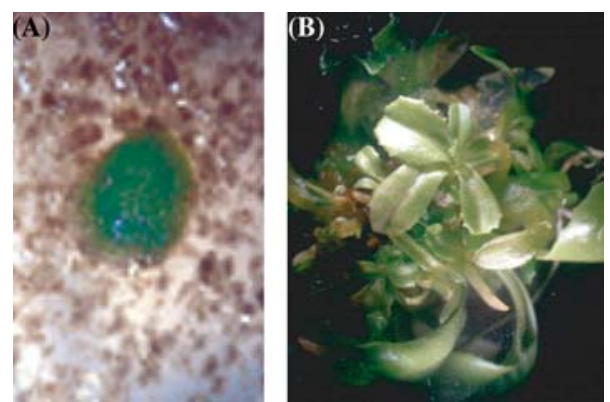

Figure 2. Regeneration of lettuce protoplasts on spectinomycin following PEG-mediated chloroplast transformation. (A) A green spectinomycin-resistant micro-callus on a background of bleached, non-spectinomycin-resistant protoplast colonies. (B) Lettuce shoots regenerating from spectinomycin-resistant callus.

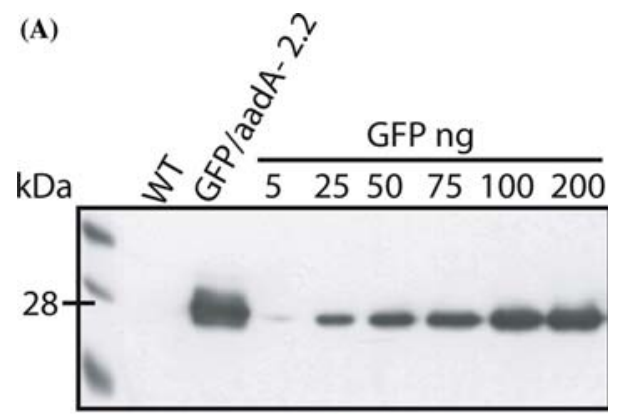

(B)

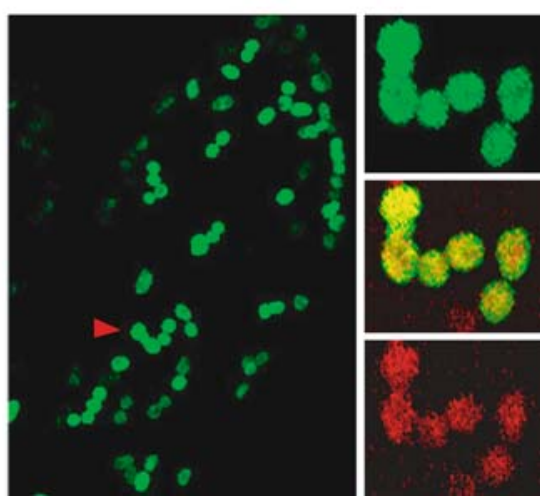

Figure 3. GFP accumulation in transplastomic lettuce callus cell lines. (A) Immunoblot of total soluble protein $(10 \mu \mathrm{g})$ from wild-type (WT) and a transformed lettuce callus cell line (GFP/aadA-2.2) separated by SDS-12\% PAGE. GFP standards $(5,25,50,75,100$ and $200 \mathrm{ng})$ were included in the gel. The membrane was incubated with rabbit antiserum to GFP and the immunoreactive bands were detected by chemiluminescence. (B) Laser scanning confocal microscope image of plastid-localized GFP in a single cell from transformed lettuce callus cell line GFP/aadA-2.2 (large image). A group of plastids (indicated by an arrow in large image) are shown under higher power on the right. Chloroplast localized GFP fluorescence (green, top panel); autofluorescence of chloroplasts (red, bottom panel), chloroplast localized GFP fluorescence superimposed on chloroplast autofluorescence (yellow, middle panel).

fluorescence was observed in all plastids. Both GFP-expressing cell lines were octoploid, as determined by flow cytometry analysis, and were not transferred to regeneration medium. Polyploid cell lines are the result of protoplast fusion events that can occur following the PEG treatment, no polyploid cell lines were generated from non-PEG treated protoplasts (data not shown). Two of the five callus lines that failed to show GFP accumulation were further assessed by PCR using trnI and aadA gene-specific primers. A $2 \mathrm{~kb}$ product was obtained in each case (data not shown) and the PCR products were gel purified and sequenced. The DNA sequence data confirmed a $g f p$ excision 
event in both callus lines mediated by recombination across the repeated Prrn region (data not shown).

One of the advantages of a plastid-based expression system in lettuce is the potential it offers both for the production and the delivery of human therapeutic proteins e.g. edible subunit vaccines. The influenza virus haemagglutinin $(H A)$ gene was used as the first candidate antigen gene for expression in the lettuce plastid. HA is a major antigenic protein on the outer surface of influenza A virus and both HA subunit protein and $H A$ DNA vaccines are known to elicit protective immune responses against viral challenge in mice (Saelens et al., 1999; Johnson et al., 2000; Ross et al., 2000). The dicistronic LEC1 expression cassette (Figure 1C) contains the aadA gene and the $H A$ gene under the control of the lettuce $(L s)$ $r r n$ operon promoter ( $\mathrm{P} L s-r r n)$ and lettuce $p s b A 3^{\prime}$ sequence $\left(3^{\prime} L s-p s b A\right)$. A dicistronic construct was built to avoid having duplicated $r r n$ promoter sequences in the expression cassette. Dicistronic constructs have been shown to generate significant levels of recombinant protein expression in tobacco plastids (Daniell et al., 1998, De Cosa et al., 2001, Lee et al., 2003, Jeong et al., 2004). The $H A$ gene is preceeded by an 18 bp synthetic leader that includes a Shine-Dalgarno-like sequence (typically GGAGG) that is required for translation (Svab and Maliga, 1993; Hirose and Sugiura 2004). LEC1 was inserted into pLCV2 at the unique $P a c \mathrm{I}$ and $A s c \mathrm{I}$ cloning sites. PEG-mediated transformation experiments with pLCV2-LEC1 generated five independent spectinomycin-resistant cell lines that were all transplastomic and heteroplasmic for the LEC1 insertion as determined by PCR analyses using various combinations of PCR primers designed against vector, expression cassette, and flanking genomic DNA sequences (data not shown). Three independent plant lines (LEC1$1.2,2.2$, and 3.1) regenerated from the spectinomycin-resistant calli approximately 6 weeks after transfer to regeneration medium containing spectinomycin $(500 \mathrm{mg} / 1$; Figure 2B). Flow cytometry analyses showed that two of the transformed plant lines were diploid (LEC1-2.2 and 3.1) and the third (LEC1-1.2) was tetraploid. When these three lines were grown to flowering, the two diploid lines produced normal flowers that set seed (data not shown) whereas the tetraploid line produced abnormal flowers that failed to set seed even after selfing or reciprocal crossing with several lettuce cultivars.

Seed harvested from three self-pollinated LEC12.2 primary regenerants $(\mathrm{A}, \mathrm{B}$ and $\mathrm{C})$ produced $100 \%$ green, spectinomycin-resistant seedlings when sown on spectinomycin-containing medium (500 mg/1; Figure 4, and data not shown). $T_{1}$ plants from the LEC1-2.2A line were used to pollinate a male-sterile, wild-type lettuce line Ms 7 (Ryder, 1971). A batch of 1200 seeds obtained from this cross were cultured on spectinomycin-containing medium $(500 \mathrm{mg} / \mathrm{l})$ and produced $100 \%$ bleached, spectinomycin-susceptible, seedlings (Figure 4, and data not shown) indicating that the transformed plastids were not transmitted via pollen.

The ratio of transformed to non-transformed chloroplast DNA in $\mathrm{T}_{1}$ plants from two of the

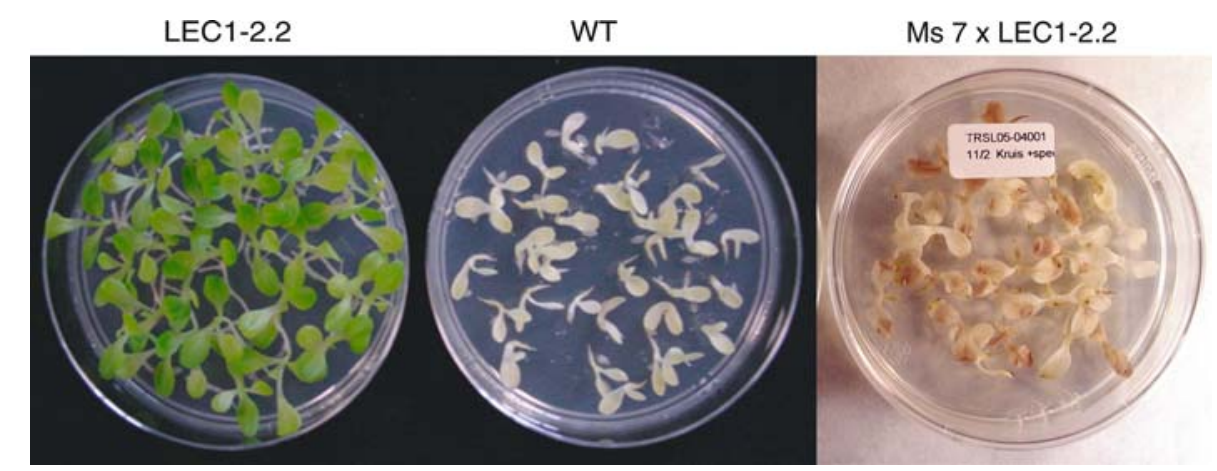

Figure 4. Spectinomycin-resistance in $\mathrm{T}_{1}$ transplastomic lettuce transformed with pLCV2-LEC1. Seed harvested from the self-pollinated primary regenerant LEC1-2.2 showing 100\% green, spectinomycin-resistant seedlings when cultured on spectinomycin-containing medium $(500 \mathrm{mg} / \mathrm{l})$. Wild-type lettuce seed showing $100 \%$ spectinomycin-susceptible seedlings when cultured on the same medium. Seeds obtained from a cross between male sterile, wild-type lettuce line Ms 7 and LEC1-2.2 also showing 100\% spectinomycin-susceptible seedlings when cultured on the same medium. 
three inbred lines (LEC1-2.2A and B) was assessed by Southern blot hybridization using a trnI-genespecific probe (Figure 5A). As expected, the trnI probe hybridized to a single $9.9 \mathrm{~kb}$ DNA fragment in wild-type DNA cut with the restriction enzyme SacI (Figure 5A). The trnI probe hybridized to a single $13.1 \mathrm{~kb} \mathrm{SacI}$ fragment in DNA isolated from the two $T_{1}$ transplastomic lines (Figure 5A), indicating that the entire LEC1 expression cassette was inserted into the plastid genome in these lines. The absence of the $9.9 \mathrm{~kb}$ wild-type band in DNA isolated from the transplastomic plants indicates that these plants were homoplasmic for the insertion (Figure 5A). An influenza $H A$ gene-specific probe hybridized to the $13.1 \mathrm{~kb} S a c$ I fragment in the transformed plants and did not hybridize to wild-type DNA (Figure 5A).

Transcription of the aadA and $H A$ genes in the same two LCV2-LEC1 transformed lines was assessed by Northern blot analysis (Figure 5B). Total RNA from the two transplastomic inbred lines and from wild-type lettuce plants was probed with aadA and $H A$ gene-specific probes. Both probes hybridized to a single $3.2 \mathrm{~kb}$ transcript in the two transgenic lines, which is the expected size of the $\operatorname{aadA} / H A$ dicistronic transcript. Neither probe hybridized to wild-type RNA. HA protein accumulation was assessed in both young and mature leaf tissue from the two transgenic lines by immunoblotting, however, HA protein could not be detected in either case (data not shown). Other studies have also reported difficulty in achieving expression of a viral antigenic protein and a viral antigenic peptide in plant plastids (Birch-Machin et al., 2004, Molina et al., 2004). It is likely that the viral $H A$ gene construct will require additional elements that could confer protein stability, such as candidate $\mathrm{N}$-terminal or $\mathrm{C}$-terminal fusions, to bring about protein accumulation in the lettuce plastid.

\section{Discussion}

Here we report PEG-mediated, stable transformation of lettuce plastids resulting in fertile, homoplasmic transgenic lines. Targeted integration of two expression cassettes was achieved using the pLCV2 vector that contains the lettuce $\operatorname{trn} A$ and trnI genes as target sites for homologous recombination into the inverted repeat region of the
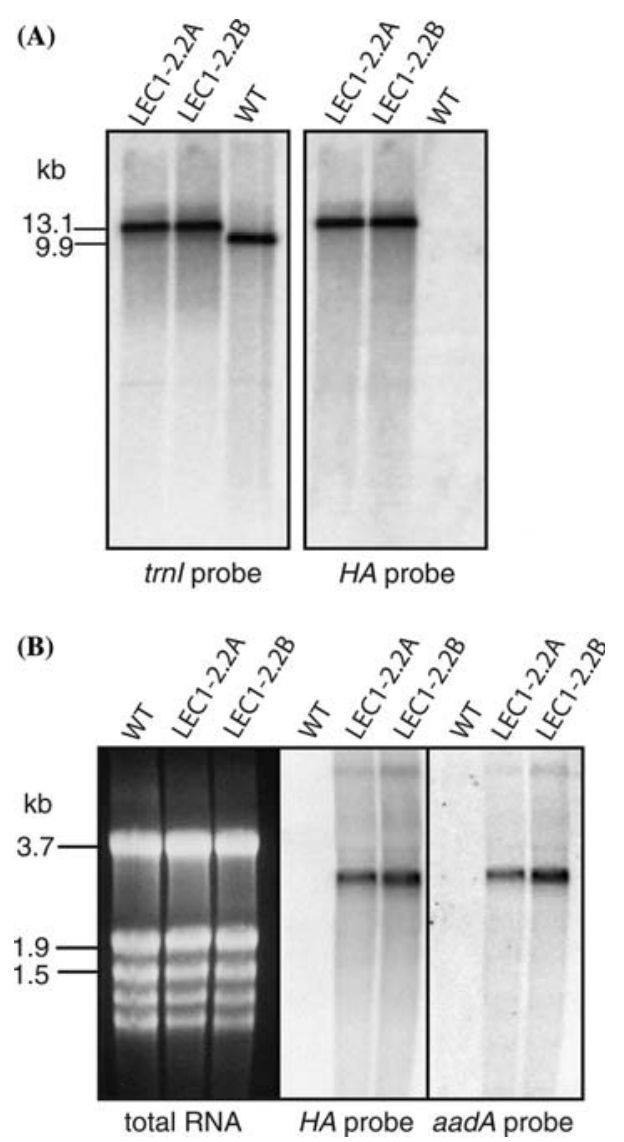

Figure 5. (A) Southern blot analysis of transplastomic lettuce plants. DNA from wild-type and $\mathrm{T}_{1}$ plant lines (LEC1-2.2A and LEC1-2.2B) was cut with SacI, separated by electrophoresis on a $1 \%$ agarose gel, and blotted onto nylon membrane. The blot was hybridized with a trnI-gene-specific probe then stripped and re-hybridized with a $H A$ gene-specific probe. The trnI probe is expected to hybridize to a $9.9 \mathrm{~kb}$ DNA fragment in wild-type DNA cut with SacI. (B) Northern blot analysis of transplastomic lettuce plants. Total RNA from wild-type (WT) and transplastomic $\mathrm{T}_{1}$ lines LEC1-2.2A and LEC1-2.2B was separated by electrophoresis on a $1 \%$ agarose/formaldehyde gel and blotted onto nylon membrane. The blot was hybridized with a $H A$ gene-specific probe then stripped and re-hybridized with an aadA gene-specific probe.

lettuce plastid genome. The $\mathrm{pLCV} 2$ vector is based on the universal chloroplast integration vector pSBL that has been used to transform the tobacco chloroplast genome (Daniell et al., 1998, De Cosa et al., 2001). pSBL has been proposed as a universal vector suitable for plastid transformation of other plant species because the $\operatorname{trn} A$ and trnI gene order is conserved in a wide range of plant species and because chloroplast DNA sequences are generally highly conserved at the 
nucleotide sequence level (Daniell et al., 1998). Although gene order is conserved in lettuce, the DNA sequence of the lettuce $\operatorname{trn} A$ and $\operatorname{trn} I$ genes reveals two DNA segments of 231 and $101 \mathrm{bp}$ that are absent from the corresponding tobacco sequence. Whether these sequence differences are sufficient to preclude lettuce chloroplast transformation with tobacco pSBL vectors has not been determined. However, at the very least, it might be expected that tobacco $\mathrm{pSBL}$ vectors might reduce the transformation frequency obtained.

On the other hand, this study shows that tobacco gene regulatory sequences are sufficent to achieve transgene expression in the lettuce plastid. Other researchers have demonstrated functionality of the tobacco chimeric rrn promoter (Svab and Maliga, 1993) in potato (Sidorov et al., 1999), tomato (Ruf et al., 2001), petunia (Zubko, et al., 2004), Arabidopsis (Sikdar et al., 1998, Sriraman et al., 1998), oilseed rape (Hou et al., 2003; Skarjinskaia et al., 2003), and soybean (Dufourmantel et al., 2004) plastids. Thus, these results indicate that tobacco gene regulatory sequences can be used for plastid-based expression of transgenes in a range of solanaceous and nonsolanaceous plant species. Plastid-based GFP accumulation, to levels equivalent to $1 \% \mathrm{TSP}$, was observed in lettuce callus tissue transformed with a GFP/aadA construct. GFP accumulation in lettuce is less than the 5.5\% TSP levels obtained in tobacco with a similar gene construct (Newell et al., 2003). The lower level of expression in lettuce is likely due to the fact that GFP was assessed in heteroplasmic callus tissue whereas in tobacco GFP was assessed in leaves of homoplasmic plant lines. Only two of the seven transplastomic cell lines assessed showed detectable GFP accumulation. PCR and DNA sequence analyses confirmed that lack of GFP in two of the nonexpressing lines (the three others were not tested) is due to $g f p$ excision events in these cell lines mediated by recombination across the repeated $r r n$ promoter sequences upstream of the $g f p$ and aad $A$ genes (Figure 1C, Iamtham and Day, 2000). The aadA gene confers resistance to both spectinomycin and streptomycin (Svab et al., 1990) and selection of lettuce transformants was achieved using the non-lethal selective agent spectinomycin. The frequency of lettuce plastid transformation was estimated at 1-2 spectinomycin-resistant cell lines per $10^{6}$ viable protoplasts (based on four independent transformation experiments that generated spectinomycin-resistant cell lines). This is significantly lower than the tobacco transformation frequency obtained using a comparable transformation approach that achieved 20-40 spectinomycin-resistant cell lines per $10^{6}$ treated protoplasts (Koop et al., 1996). However, 13-55\% of the tobacco spectinomycin-resistant cell lines were shown not to be true plastid transformants and spectinomycin resistance was conferred either by spontaneous mutation or nuclear transformation events (Koop et al., 1996). In contrast, 100\% of the spectinomycin-resistant lettuce cell lines generated in this study were true plastid transformants (as determined by PCR) and no spectinomycin-resistant spontaneous mutants or nuclear transformants were obtained. The main limitation of the lettuce PEG-mediated transformation protocol is the high frequency of polyploid cell lines that were obtained and which were probably due to protoplast fusion events mediated by the PEG treatment. Consequently, only approximately $30 \%$ of the regenerated spectinomycin-resistant plants were diploid, and only the diploid plants were fertile and set seed.

One of the advantages of plastid transformation is the potential for high levels of accumulation of heterologous proteins. Several functional therapeutic proteins have been expressed in tobacco chloroplasts at levels that rival or exceed those of conventional animal or bacterial bioreactors (Fischer et al., 2004). A recent report described plastid-based expression of tetanus toxin fragment C from Clostridium tetani in tobacco to levels equivalent to $25 \%$ TSP (Tregoning et al., 2003). In this case, the plastid-expressed subunit vaccine was comparable to the conventional vaccine in terms of protection afforded against tetanus toxin challenge in a mouse model. The lettuce plastid offers several advantages as a production system for high value human therapeutic proteins compared to tobacco: (1) most of the plant is leaf tissue and this tissue contains the greatest number of plastids per cell; (2) unlike tobacco, lettuce has no toxic alkaloids that need to be removed, adding to protein purification and downstream processing costs; (3) lettuce is a relevant human foodstuff that can be consumed without cooking. Thus, lettuce plastid transformation offers the possibility of both a production and a delivery system for human health products such as subunit vaccines 
that are capable of stimulating a therapeutic response via the gut. The influenza virus A haemagglutinin gene $(H A)$ is the first potential subunit vaccine gene to be introduced into the lettuce plastid genome. The LEC1 dicistronic cassette contains the aadA gene and the $H A$ gene under the control of the lettuce rrn operon promoter $(\mathrm{P} L s-r r n)$. A similar dicistronic format was used to co-express aadA with various other transgenes in the tobacco plastid including $g f p$ (Jeong et al., 2004), 5-enol-pyruvate shikimate-3phosphate synthase (Daniell et al., 1998), the Cry2Aa2 operon (De Cosa et al., 2001), and a trehalose phosphate synthase gene (Lee et al., 2003). Although fertile, homoplasmic, plastidtransformed plant lines were obtained, only mRNA, and no HA protein, was detected in these lines (data not shown), even though HA protein was detected at a high level in E. coli containing this construct (data not shown). Recent studies have demonstrated instability of candidate human and viral proteins expressed in plant plastids (Leelavathi and Reddy 2003; Birch-Machin et al., 2004, Molina et al., 2004). At the moment there are still no hard-and-fast rules that can be applied to predict if a foreign protein will accumulate in plant plastids. Pre-screening of plastid transgene expression cassettes in E. coli is not a reliable predictor of plastid expression levels (Magee et al., 2004). Work in tobacco has shown that levels of plastid-based protein accumulation are very much dependent on optimizing expression cassette design, e.g. choice of promoter, choice of $5^{\prime}$ and $3^{\prime}$ untranslated regions, and choice of N-terminal fusions (Maliga, 2003). Molina et al. (2004) only achieved high levels of a viral antigenic peptide in tobacco plastids as a C-terminal translational fusion with cholera toxin B subunit or GFP. Now that a plastid transformation system has been developed for lettuce the future focus will be to generate a range of cassettes that utilize different types of translational control in order to maximise plastid-based protein production in this species.

\section{Acknowledgements}

This work was funded under the EU Fifth Framework initiative, grant number QLK-CT1999-00692. We thank Dr. Paul Anthony, Dr. Mike Davey and Dr. Greg Nugent for helpful discussions. We thank Dr. Bridget Hogg for technical assistance.

\section{References}

Bendich, A.J 1987. Why do chloroplasts and mitochondria contain so many copies of their genome? BioEssays 6: 279-282.

Birch-Machin, I., Newell, C.A., Hibberd, J.M. and Gray, J.C. 2004. Accumulation of rotavirus VP6 protein in chloroplasts of transplastomic tobacco is limited by protein stability. Plant Biotech. J. 2: 261-270.

Birky, C.W. 2001. The inheritance of genes in mitochondria and chloroplasts: laws, mechanisms, and models. Ann. Rev. Genet. 35: 125-148.

Boynton, J.E., Gillham, N.W., Harris, E.H., Hosler, J.P., Johnson, A.M., Jones, A.R., Randolf-Anderson, B.L., Robertson, D., Klein, T.M., Shark, K.B. and Sanford, J.C. 1988. Chloroplast transformation in Chlamydomonas with high velocity microprojectiles. Science 240: 1534-1538.

Daniell, H., Datta, R., Varma, S., Gray, S. and Lee, S.-B. 1998. Containment of herbicide resistance through genetic engineering of the chloroplast genome. Nat. Biotechnol. 16: $345-348$.

Datta, K. and Datta, S.K. 1999. Transformation of rice via PEG-mediated DNA uptake into protoplasts. Meth. Mol. Biol. 111: 335-347.

De Cosa, B., Moar, W., Lee, S.-B., Miller, M. and Daniell, H. 2001. Overexpression of Bt Cry2Aa2 operon in chloroplasts leads to formation of insecticidal crystals. Nat. Biotechnol. 19: 71-74.

Dufourmantel, N., Pelissier, B., Garcon, F., Peltier, G., Ferullo, J-M. and Tissot, G. 2004. Generation of fertile transplastomic soybean. Plant Mol Biol. 55: 479-489.

Fischer, R., Stoger, E., Schillberg, S., Christou, P. and Twyman, R.M. 2004. Plant-based production of biopharmaceuticals. Curr. Opin. Plant Biol. 7: 152-158.

Frearson, E.M., Power, J.B. and Cocking, E.C. 1973. The isolation, culture and regeneration of petunia leaf protoplasts. Dev. Biol. 33: 130-137.

Gamborg, O.L., Miller, R.A. and Ojima, K. 1968. Nutrient requirements of suspension cultures of soybean root cells. Exp. Cell Res. 50: 151-158.

Glimelius, K. 1984. High growth rate and regeneration capacity of hypocotyl protoplasts in some Brassicaceae. Physiol. Plant. 61: 38-44.

Golds, T., Maliga, P. and Koop, H.-U. 1993. Stable plastid transformation in PEG-treated protoplasts of Nicotiana tabacum. Bio/Technology 11: 95-97.

Hirose, T. and Sugiura, M. 2004. Functional Shine-Dalgarnolike sequences for translational initiation of chloroplast mRNAs. Plant Cell Physiol. 45: 114-117.

Hou, B-K., Zhou, Y-H., Wan, L-H., Zhang, Z-L., Shen, G-F., Chen, Z-H. and Hu, Z-M. 2003. Chloroplast transformation in oilseed rape. Transgenic Res. 12: 111-114.

Iamtham, S. and Day, A. 2000. Removal of antibiotic resistance genes from transgenic tobacco plastids. Nat. Biotechnol. 18: $1172-1176$.

Jansen, R.K. and Palmer, J.D. 1987. Chloroplast DNA from lettuce and Barnadesia (Asteraceae): structure, gene 
localization, and characterization of a large inversion. Curr. Genet. 11: 553-564.

Jeong, S.W., Jeong, W.J., Woo, J.W., Choi, D.W., Park, Y.I. and Liu, J.R. 2004. Dicistronic expression of the green fluorescent protein and antibiotic resistance genes in the plastid for selection and tracking of plastid-transformed cells in tobacco. Plant. Cell. Rep. 22: 747-751.

Johnson, P.A., Conway, M.A., Daly, J., Nicolson, C., Robertson, J. and Mills, K.H. 2000. Plasmid DNA encoding influenza virus haemagglutinin induces Th1 cells and protection against respiratory infection despite its limited ability to generate antibody responses. J. Gen. Virol. 81: 1737-1745.

Khan, M.S. and Maliga, P. 1999. Fluorescent antibiotic resistant marker to track plastid transformation in higher plants. Nat. Biotechnol. 17: 910-915.

Koop, H.-U., Steinmuller, K., Wagner, H., Rossler, C., Eibl, C. and Sacher, L. 1996. Integration of foreign sequences into the tobacco plastome via polyethylene glycol-mediated protoplast transformation. Planta 199: 193-201.

Kumar, S., Dhingra, A. and Daniell, H. 2004. Stable transformation of the cotton plastid genome and maternal inheritance of transgenes. Plant Mol. Biol. 56: 203-216.

Kumar, S., Dhingra, A. and Daniell, H. 2004. Plastid-expressed betaine aldehyde dehydrogenase gene in carrot cultured cells, roots, and leaves confers enhanced salt tolerance. Plant. Physiol. 136: 2843-2854.

Lee, S.B., Kwon, H.B., Kwon, S.J., Park, S.C., Jeong, M.J., Han, S.E., Byun, M.O. and Daniell, H. 2003. Accumulation of trehalose within transgenic chloroplasts confers drought tolerance. Mol. Breed. 11: 1-13.

Leelavathi, S. and Reddy, V.S. 2003. Chloroplast expression of His-tagged GUS-fusions: a general strategy to overproduce and purify foreign proteins using transplastomic plants as bioreactors. Mol. Breed. 11: 49-58.

Magee, A.M., Horváth, E.M. and Kavanagh, T.A. 2004. Prescreening plastid transgene expression cassettes in Escherichia coli may be unreliable as a predictor of expression levels in chloroplast-transformed plants. Plant Sci. 166: 1605-1611.

Maliga, P. 2003. Progress towards commercialization of plastid transformation technology Trends Biotechnol. 21: 20-28.

Menczel, L., Nagy, F., Kiss, Z.R. and Maliga, P. 1981. Streptomycin resistant and sensitive somatic hybrids of Nicotiana tabacum + Nicotiana knightiana: correlation of resistance to N. tabacum plastids. Theor. Appl. Genet. 59: 191-195.

Molina, A., Hervás-Stubbs, S., Daniell, H., Mingo-Castel, A.M. and Veramendi, J. 2004. High-yield expression of a viral peptide animal vaccine in transgenic tobacco chloroplasts Plant. Biotech. J. 2: 141-153.

Murashige, T. and Skoog, F. 1962. A revised medium for rapid growth and bioassays with tobacco cell cultures. Physiol. Plant. 15: 473-497.

Newell, C.A., Birch-Machin, I., Hibberd, J.M. and Gray, J.C. 2003. Expression of green fluorescent protein from bacterial and plastid promoters in tobacco chloroplasts. Transgenic Res. 12: 631-634.

O’Neill, C., Horváth, G.V., Horváth, E., Dix, P.J. and Medgyesy, P. 1993. Chloroplast transformation in plants: polyethylene glycol (PEG) treatment of protoplasts is an alternative to biolistic delivery systems. Plant J. 3: 729-738.
Pyke, K.A. 1999. Plastid division and development. Plant Cell 11: $549-556$.

Ross, T.M., Xu, Y., Bright, R.A. and Robinson, H.L. 2000. C3d enhancement of antibodies to hemagglutinin accelerates protection against influenza virus challenge. Nat. Immunol. 1: $127-131$.

Ruf, S., Hermann, M., Berger, I.J., Carrer, H. and Bock, R. 2001. Stable genetic transformation of tomato plastids and expression of a foreign protein in fruit. Nat. Biotechnol. 19: $870-875$.

Ryder, E.J. 1971. Genetic studies in lettuce (Lactuca sativa L). J. Am. Soc. Hort. Sci. 96: 826-828.

Saelens, X., Vanlandschoot, P., Martinet, W., Maras, M., Neirynck, S., Contreras, P., Fiers, W. and Jou, W.M. 1999. Protection of mice against a lethal influenza virus challenge after immunization with yeast-derived secreted influenza virus hemagglutinin. Eur. J. Biochem. 260: $166-175$.

Schenk, R.U. and Hildebrandt, A.C. 1972. Medium and techniques for induction and growth of monocotyledonous and dicotyledonous plant cell cultures. Can. J. Bot. 50: 199-204.

Sidorov, V.A., Kasten, D., Pang, S.Z., Hajdukiewicz, P.T., Staub, J.M. and Nehra, N.S. 1999. Stable chloroplast transformation in potato: use of green fluorescent protein as a plastid marker. Plant J. 19: 209-216.

Sikdar, S.R., Serino, G., Chaudhuri, S. and Maliga, P. 1998. Plastid transformation in Arabidopsis thaliana. Plant Cell Rep. 18: 20-24.

Skarjinskaia, M., Svab, Z. and Maliga, P. 2003. Plastid transformation in Lesquerella fendleri, an oilseed Brassicacea. Transgenic Res. 12: 115-122.

Southern, E.M. 1975. Detection of specific sequences among DNA fragments separated by gel electrophoresis. J. Mol. Biol. 98: 503-517.

Sriraman, P., Silhavy, D. and Maliga, P. 1998. Transcription from heterologous rRNA operon promoters in chloroplasts reveals requirements for specific activating factors. Plant Physiol. 117: 1495-1499.

Staub, J.M. and Maliga, P. 1992. Long regions of homologous DNA are incorporated into the tobacco plastid genome by transformation. Plant Cell 4: 39-45.

Staub, J.M. and Maliga, P. 1995. Expression of a chimeric uidA gene indicates that polycistronic mRNAs are efficiently translated in tobacco plastids. Plant J. 7: 845-848.

Svab, Z., Hajdukiewicz, P. and Maliga, P. 1990. Stable transformation of plastids in higher plants. Proc. Natl. Acad. Sci. USA 87: 8526-8530.

Svab, Z. and Maliga, P. 1993. High-frequency plastid transformation in tobacco by selection for a chimeric aadA gene. Proc. Natl. Acad. Sci. USA 90: 913-917.

Tregoning, J.S., Nixon, P., Kuroda, H., Svab, Z., Clare, S., Bowe, F., Fairweather, N., Ytterberg, J., van Wijk, K.J., Dougan, G. and Maliga, P. 2003. Expression of tetanus toxin fragment $\mathrm{C}$ in tobacco chloroplasts. Nucl. Acids Res. 31: 1174-1179.

Wakasugi, T., Sugita, M., Tsudzuki, T. and Sugiura, M. 1998. Updated gene map of tobacco chloroplast DNA. Plant Mol. Biol. Rep. 16: 231-241.

Zubko, M.K., Zubko, E.I., van Zuilen, K., Meyer, P. and Day, A. 2004. Stable transformation of petunia plastids. Transgenic Res. 13: 523-530. 